\title{
The Value of Hysteroscopy in the Diagnosis of Endometrial Cancer
}

\author{
Oliveres-Amor C*, Pampalona J R, Bastos MD, \\ García AG, Pruñonosa J CM and Torras PB \\ Department of Obstetrics and Gynecology, Consorci \\ Sanitari de l'Anoia, Igualada, Spain \\ *Corresponding author: Carla Oliveres Amor, \\ Department of Obstetrics and Gynecology, Consorci \\ Sanitari de l’Anoia, Igualada, Spain
}

Received: March 09, 2018; Accepted: April 12, 2018; Published: May 07, 2018

\section{Abbreviations}

AUB: Abnormal uterine bleeding; TVUS: Transvaginal ultrasonography; ET: Endometrial thickness; PMB: Postmenopausal bleeding; D\&C: Dilatation and curettage

\section{Introduction}

Endometrial cancer is the most common malignancy of the female genital tract in developed countries, and the second in mortality after ovarian cancer [1]. For the last 30 years there has been an increase in the number of diagnoses. Its incidence is rising among pre and postmenopausal women; every year, about 200.000 new endometrial cancers are diagnosed around the world and an estimated 50.000 women die from this illness [2].

The risk of endometrial cancer is positively correlated with the excessive endometrial stimulation with estrogen, associated with older age, early menarche, late menopause, nulliparity, obesity, family history of endometrial cancer, Polycystic Ovarian Syndrome, as well as hormone replacement therapy [3]. Other risk factors include personal history of breast cancer and genetic predisposition (Lynch syndrome) [4]. Diabetes, hypertension, and geographical and socioeconomic factors are still inconclusive [5].

The most common symptom of endometrial cancer is abnormal uterine bleeding (AUB). However, up to $20 \%$ of patients can be asymptomatic at the time of diagnosis [6-8].
The most important prognostic features for endometrial cancer are the stage (FIGO), the myometrial infiltration, histological type and differentiation grade [9].

The Transvaginal Ultrasonography (TVUS) is the gold standard for the diagnosis of endometrial pathology. It shows endometrial thickness and heterogeneous variations within the echogenicity of the endometrium [10]. Because of its non-invasive nature and its high accuracy, it is used as the first line endometrial diagnosis. Currently, the cut-off value for Endometrial Thickness (ET) in asymptomatic women is not well established $[11,12]$ yet.

Some authors suggest that an endometrial thickness cut-off value of $10 \mathrm{~mm}$ does not miss any cases of endometrial cancer $[13,14]$. Therefore, the hysteroscopy examination and the sequential endometrial biopsy for the histopathological examination of tissue are essential to get an endometrial carcinoma diagnosis.

Hysteroscopy allows direct visualization and examination of the uterine cavity. In some cases, it can also suspect malignant pathologies and, in these circumstances, hysteroscopy allows to perform an endometrial sampling or removal of the endometrial pathology in an outpatient setting during the same procedure $[15,16]$. Although the final diagnosis is histologic, there are some morphological hysteroscopic criteria that are indicative of endometrial cancer.

The purpose of this study is to assess the diagnostic accuracy of hysteroscopy and endometrial biopsy in the diagnosis of malignant 
Table 1: Suspected cases with endometrial neoplasia correlated with histological examination.

\begin{tabular}{|c|c|}
\hline & $\begin{array}{c}\text { Endometrial } \\
\text { carcinoma }\end{array}$ \\
\hline $\begin{array}{c}\text { Suspected endometrial carcinoma on } \\
\text { hysteroscopic view }\end{array}$ & 24 \\
\hline Histologic diagnosis of endometrial carcinoma & 26 \\
\hline False positive & 0 \\
\hline False negative & 2 \\
\hline
\end{tabular}

endometrial lesions.

\section{Material and Methods}

A retrospective study was carried out in which a total of 891 patients with outpatient hysteroscopy were included. The hysteroscopy was performed between July 2012 and December 2015 in Igualada's Hospital.

The procedures were carried out in ambulatory care with no anesthesia or sedation of any sort. No cervical or endometrial preparation was performed pre-intervention.

The procedure was conducted by two experienced hysteroscopists
(MDB, JRP) using one of the two hysteroscopic systems (the Truclear 5.0 Tissue Removal System (Smith \& Nephew) with mechanical energy or the Versapoint Bipolar Electro surgery System (Gynecare; Ethicon Inc.) with bipolar energy).

All the procedure involved a systematic examination of the uterine cavity and an endometrial eye-directed biopsy in the suspected pathology, or at random if we had not suspicion of any pathology. The standard forceps with a polyp grip was used for extracting intrauterine tissue.

With the hysteroscopic reports, patients were divided into three diagnostic categories for the endometrium classification: no pathology, benign pathology and suspected malignancy.

Other variables were assessed: Socio-demographic data and obstetrician antecedents (parity: Nulliparous, 1 delivery, vaginal $v s$. cesarean; hormonal status: menopause $v s$. no menopause).

Statistical analysis: for statistical analysis, we have provided a general description of the variables included in the study (sensitivity, specificity, positive predictive value, and negative predictive value).

Table 2: Patient's age and symptomatology, echography suspicion and malignancy during hysteroscopy, as well as the anatomopathologic result of the endometrial biopsy performed during hysteroscopy and post-surgical stage.

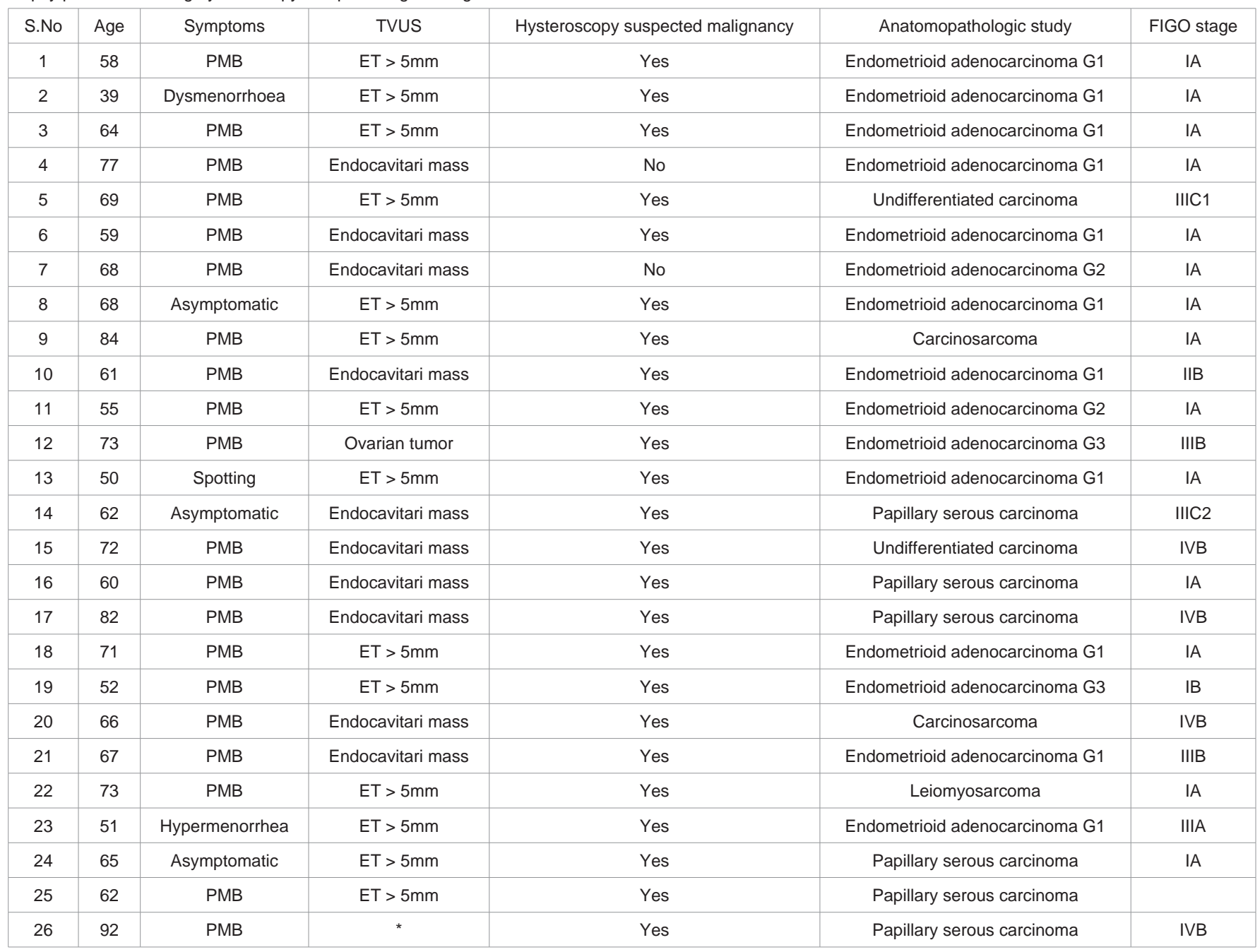




\section{Results}

Of the total outpatient hysteroscopy that was carried out, we obtained a total of 26 patients with histologic diagnoses of endometrial cancer. Among them, the hysteroscopic examiner suspected endometrial cancer in 24 cases (Table 1 and Table 2). There were two cases of false negatives in which the examiner described the hysteroscopic image as large polyps. The other patients were classified in the category no pathology $(n=452)$ and benign pathology $(n=415)$.

The mean age of these patients was 65.27 (range 39-92), and $88.5 \%$ were postmenopausal. Table 3 shows the clinical, echography and hysteroscopy variables, and anatomopathologic results of 26 patients with diagnosis of endometrial carcinoma.

Among the most frequent personal history, the highlights are hypertension (13/26), obesity $(6 / 26)$, diabetes mellitus $(7 / 26)$, dyslipedemia (7/26) and psychiatric disorders such as depression $(6 / 26)$. None of the patients were undergoing treatment with tamoxifen or hormone replacement therapy.

The most common type of cancer was endometrioid adenocarcinoma (50\%) with histologic subtypes G1 (42.3\%). However, in the endometrioid carcinomas there are also some cases of advanced stages, less frequent than in the most aggressive histological subtypes. Only 5 out of 15 endometrioid carcinomas were not an IA stage in the FIGO classification.

In our study, we obtained a sensitivity of $92.3 \%$ with hysteroscopy for the diagnosis of endometrial cancer and it presents excellent specificity (Table 3). The final diagnosis was reached with pathological study sample obtained during hysteroscopy.

\section{Discussion}

The hysteroscopy is an accurate diagnostic method to discriminate between normal and pathologic endocavitary conditions in both symptomatic and asymptomatic women [17]. In the current study, for the assessment of endometrial carcinoma, hysteroscopy has obtained a sensitivity of $92.3 \%$, a specificity of $99.1 \%$, a positive predictive value of $75.0 \%$, and a negative predictive value of $99.7 \%$. In addition, hysteroscopy has the capability of reducing sampling errors, very common in blind dilatation and curettage (D\&C) technique, which can miss focal pathology or endometrial precancerous lesions [18].

Many studies have described hysteroscopic features of neoplastic morphology [19-21] and one group conducted a study to develop a systematic score system for identification of endometrial cancer [22]. Despite the higher accuracy of the score system compared to subjective evaluation of the endometrium, it must be evaluated in larger populations and not selected patients in order to generalize its use. However, performing an eye-directed biopsy during the hysteroscopy has been shown to be the best strategy, not only to diagnose a neoplasm but to accurately differentiate benign pathology such as endometrial polyps from pre-cancerous lesions like endometrial hyperplasia $[15,23]$.

Although it has been shown that the best test to study the endometrial pathology is hysteroscopy, usually the endometrial study begins with a TVUS. Sonographic measurement of endometrial thickness is an accurate and easy procedure to determine whether
Table 3: Sensitivity, specificity, positive and negative predictive values for diagnosis of endometrial cancer on hysteroscopic view.

\begin{tabular}{|c|c|}
\hline & Presence of endometrial carcinoma (\%) \\
\hline Sensitivity & $92.3(24 / 26)$ \\
\hline Specificity & $99.1(857 / 865)$ \\
\hline Positive predictive value & $75.0(24 / 32)$ \\
\hline Negative predictive value & $99.7(857 / 859)$ \\
\hline
\end{tabular}

further investigations are needed to rule out malignancy. Different cut-off values for endometrial thickness have been used, but guidelines recommend a cut-off value of 3 to $5 \mathrm{~mm}$ below which endometrial cancer is unlikely in symptomatic women $[24,25]$. This limit is not well established in asymptomatic women in whom an endometrial thickness of up to $10 \mathrm{~mm}$ could be normal.

Despite the high sensibility of transvaginal ultrasound to diagnose intrauterine disorders, endometrial thickness or Doppler ultrasonography measured by transvaginal ultrasonography has low specificity for predicting malignant endometrial disorders $[16,26]$.

The literature supports that the combined use of ultrasonography and hysteroscopy, with eye directed biopsy, is the most appropriate diagnostic strategy for not infradiagnosticating endometrial pathology such as cancer [27]. The importance of hysteroscopy is also shown in the present study, in which $92.3 \%$ of the cases of endometrial cancer were suspected by hysteroscopy and confirmed with eye-directed biopsy on histologic examination. On two occasions, the neoplasm was not suspected, neither by the hysteroscopy nor the ultrasound study which suspected endometrial polyps. It must be highlighted that the anatomopathological study showed focus of endometrioid carcinoma in the polyp, and in these cases, have a suspect that can be more complicated for the specialist.

Therefore, it is important to study all post-menopausal metrorrhagia, because it is usually the main clinical sign of endometrial carcinoma. The prevalence of this symptom in endometrial carcinoma-afflicted patients' highlights the need to study these patients to rule out endometrial pathology. This fact is also evident in our sample, where $88.5 \%$ of patients are post-menopausal and the most frequent symptom within these was post-menopausal bleeding. For these reasons, hysteroscopy should be considered in all women with postmenopausal uterine bleeding due to the increased risk of endometrial carcinoma within this group $[27,28]$.

On the other hand, asymptomatic patients with suspected endometrial pathology by TVUS can't be despised. In the sample of the present study, it is observed that asymptomatic patients may have high-grade histologic subtypes such as papillary serous carcinoma and present with advanced stage carcinoma. At the same time, it is important not to forget the premenopausal patients, poorly rethought in our study sample (3/26), but with an incidence of endometrial carcinoma increasing [3].

\section{Conclusions}

Hysteroscopic view presents excellent specificity for endometrial cancer (99.1\%) and good sensitivity for endometrial cancer (92.3\%). Despite the good validity of hysteroscopic view, biopsy is essential for endometrial hyperplasia and cancer diagnosis. 


\section{References}

1. American Cancer Society: Cancer Facts and Figures 2016. Atlanta, Ga: American Cancer Society. 2016

2. Bray F, Loos AH, Oostinider M, Weiderpass E. Geographic and temporal variations in cancer of the corpus uteri: incidence and mortality in pre- and post-menopausal women in Europe. Int J Cancer. 2005; 117: 123-131.

3. Moore K, Brewer MA. Endometrial Cancer: Is This a New Disease? Am Soc Clin Oncol Educ Book. 2017; 37: 435-442.

4. Ali AT. Risk factors for endometrial cancer. Ceska Gynekol. 2013; 78: 448459.

5. Renaud MC, Le T, Le T, Bentley J, Farrell S, Fortier MP, et al. Epidemiology and investigations for suspected endometrial cancer. J Obstet Gynaecol Can. 2013; 35: 380-381

6. Malkasian GD Jr, Annegers JF, Fountain KS. Carcinoma of the endometrium: Stage I. Am J Obstet Gynecol. 1980; 136: 872-888.

7. Binder PS, Mutch DG. Update on prognostic markers for endometrial cancer. Womens Health (Lond). 2014; 10: 277-288.

8. Amant F, Moerman P, Neven P, Timmerman D, Van Limbergen E, Vergote I. Endometrial cancer. Lancet. 2005; 366: 491-505.

9. Alcázar JL, Orozco R, Martinez-Astorquiza Corral T, Juez L, Utrilla-Layna J, Mínguez JA, et al. Transvaginal ultrasound for preoperative assessment of myometrial invasion in patients with endometrial cancer: A systematic review and meta-analysis. Ultrasound Obstet Gynecol. 2015; 46: 405-413.

10. Saidi MH, Sadler RK, Theis VD, Akright BD, Farhart SA, Villanueva GR. Comparison of sonography, sonohysterography and hysteroscopy for evaluation of abnormal uterine bleeding. J Ultrasound Med. 1997; 16: 587591

11. Wolfman W, Leyland N, Heywood M, Singh SS, Rittenberg DA, Soucy R, et al. Asymptomatic endometrial thickening. J Obstet Gynaecol Can. 2010; 32 990-999.

12. Giannella L, Mfuta K, Setti T, Boselli F, Bergamini E, Cerami L.B. Diagnostic accuracy of endometrial thickness for the detection of intra-uterine pathologies and appropriateness of performed hysteroscopies among asymptomatic postmenopausal women. Eur J Obstet Gynecol Reprod Biol. 2014; 177: 2933.

13. Smith-Bindman R, Weiss E, Felstein V. How thick is too thick? When endometrial thickness should promt biopsy in postmenopausal women without vaginal bleeding. Ultrasound Obstet Gynecol. 2004; 24: 558-565

14. Yasa C, Dural O, Bastu E, Gungor F, Nehir A, Cem A. Evaluation of the diagnostic role of transvaginal ultrasound measurements of endometria thickness to detect endometrial malignancy in asymptomatic postmenopausa women. Arch Gynecol Obstet. 2016: 294: 311-316.

15. Litta P, Merlin F, Saccardi C, Pozzan C, Sacco G, Fracas M, et al. Role of hysteroscopy with endometrial biopsy to rule out endometrial cancer in postmenopausal women with abnormal uterine bleeding. Maturitas. 2005; 50 : 117-123.
16. Karlsson B, Grandberg S, Wikiland M, Ylöstalo P, Torvid K, Marsal K et al. Transvaginal ultrasonography of the endometrium in women with postmenoapusal bleeding. A Nordic multicenter study. AMJ Obstet Gynecol. 1995; 172: 1488

17. Socías MT, Vargas RS, Costoya AA, Monje BR, Haye MT. Correlación de la histeroscopia y biopsia dirigida en el estudio del engrosamiento endometrial patológico por ultrasonido. Rev Chil Obstet Ginecol. 2007; 72: 99.

18. Van Hanegem N, Prins MM, Bongers MY, Opmeer BC, Sahota DS, Mol BW et al. The accuracy of endometrial sampling in women with postmenopausal bleeding: a systematic review and meta-analysis. Eur J Obstet Gynecol Reprod Biol. 2016; 197: 147-155.

19. Gaturi G, De GO, Sambruni I, Cellani F, Luerti M. Prognostic significance of hysteroscopic imaging in endometriod endometrial adenocarcinoma. Gynecol Oncol. 2001; 81: 408-413.

20. Sugimoto O. Hysteroscopic diagnosis of endometrialcarcinoma. A report of fifty-three cases examined at de Women's Clinic of Kyoto University Hospital. Am. J Obstet. Gynecol. 1975; 121: 105-113.

21. Dotto JE, Lema B, Dotto JE Jr, Hamou J. Classification of microhysteroscopic images and their correlation with histologic diagnoses. J Am Assoc Gynecol Laparosc. 2003; 10: 233-246.

22. Duhelom M, Hjorth IMD, Secher P, Jørgensen A, Croft G. Structured hysteroscopic evaluation of endometrium in women with postmenopausal bleeding. J Minim Invasive Gynaecol. 2015; 22: 1215-1224

23. Tinelli R, Tinelli FG, Cicinelli E, Malvasi A, Tinelli A. The role of hysteroscopy with eye-directed biopsy in postmenopausal women with uterine bleeding and endometrial atrophy. Menopause. 2008; 15: 737-742.

24. Tahir MM, Bigrigg MA, Browning JJ, Brookes ST, Smith PA. A randomized controlled trial comparing transvaginal ultrasound, out- patient hysteroscopy and endometrial biopsy with inpatient hysteroscopy and curettage. $\mathrm{Br} \mathrm{J}$ Obstet Gynaecol. 1999; 106: 1259-1264.

25. Timmermans A, Opmeer BC, Khan KS, Bachmann LM, Epstein E, Clark TJ, et al. Endometrial thickness measurement for detecting endometrial cancer in women with postmenopausal bleeding: A systematic review and metaanalysis. Obstet Gynecol. 2010; 116: 160-167.

26. Cavkaytar S, Kokanali MK, Ceran U, Topcu HO, Sirvan L, Doganay M. Roles of sonography and hysteroscopy in the detection of premalignant and malignant polyps in women presenting with postmenopausal bleeding and thickened endometrium. Asian Pac J Cancer Prev. 2014; 15: 5355-5358.

27. Sousa R, Silvestre M, Almeida e Sousa L, Falcao F, Silva T, et al Transvaginal ultrasonography and hysteroscopy in postmenopausal bleeding: A prospective study. Acta Obstet Gynecol Scand. 2001; 80: 856-862.

28. Epstein E, Ramirez A, Skoog L, Valentin L. Transvaginal sonography, saline contrast sonohysterography and hysteroscopy for the investigation of women with postmenopausal bleeding and endometrium $95 \mathrm{~mm}$. Ultrasound Obstet Gynecol. 2001; 18: 157-162.
Austin J Obstet Gynecol - Volume 5 Issue 5 - 2018

Submit your Manuscript | www.austinpublishinggroup.com

Oliveres-Amor et al. (C) All rights are reserved
Citation: Oliveres-Amor C, Pampalona JR, Bastos MD, García AG, Pruñonosa JCM and Torras PB. The Value of Hysteroscopy in the Diagnosis of Endometrial Cancer. Austin J Obstet Gynecol. 2018; 5(5): 1113. 